\title{
Optical Model of Laminated Remote Phosphor Films and Its Application in White LED
}

\author{
Yong-Hao Chen ${ }^{D}$, ${ }^{1}$ Ning-Ze Zhuo ${ }^{2},{ }^{2,3}$ Peng Jiang, ${ }^{1}$ Shao-Wen Cheng, \\ Peng-Fei Shen, ${ }^{4}$ and Hai-Bo Wang ${ }^{2}$ \\ ${ }^{1}$ College of Materials Science and Engineering, Nanjing Tech University, Nanjing 210009, China \\ ${ }^{2}$ Institute of Optoelectronic Materials of Light Industry, Nanjing 210015, China \\ ${ }^{3}$ Research Institute of Electric Light Source Materials, Nanjing Tech University, Nanjing 210015, China \\ ${ }^{4}$ College of Energy Science and Engineering, Nanjing Tech University, Nanjing 211816, China \\ Correspondence should be addressed to Ning-Ze Zhuo; zhuoningze89@163.com
}

Received 12 November 2018; Accepted 27 December 2018; Published 3 March 2019

Academic Editor: Fajun Zhang

Copyright (C) 2019 Yong-Hao Chen et al. This is an open access article distributed under the Creative Commons Attribution License, which permits unrestricted use, distribution, and reproduction in any medium, provided the original work is properly cited.

\begin{abstract}
Based on Mie scattering and Monte Carlo ray tracing method, the transmission process of light in the remote phosphor film is described and the optical model of red and green laminated phosphor films is constructed. The photochromic properties of the phosphor films were studied by TM-30-15 method proposed by the North American Lighting Association. The investigation discloses that the normalized cross correlation of single-layer phosphor film spectral power distribution between the simulation and experimental results is about $99 \%$, and the deviation of color coordinates is within 0.01 . Based on the monochrome phosphor optical model, we establish bicolor optical model of red and green laminated phosphor film layers to form white light and can predict its color performance. The experimental results show that the normalized cross correlation of laminated phosphor film spectral power distribution between the simulation and experiment is about $97 \%$, and the optical model of red and green laminated phosphor film can accurately predict the index $\mathrm{R}_{\mathrm{f}}$ and $\mathrm{R}_{\mathrm{g}}$. When the red and green phosphor mass ratio is $0.05: 0.5$, the simulated color is optimal, $R_{f}$ reaches 90 , and $R_{g}$ reaches 100 , whose corresponding experimental values are $R_{f}=90, R_{g}=101$.
\end{abstract}

\section{Introduction}

White light-emitting diodes (WLEDs) have been widely accepted due to, but not limited to, their energy saving, environmental protection, safety, and reliability $[1,2]$. However, the LED light is not natural light which usually has low color quality and makes us uncomfortable. High-lightefficiency but low-color-quality WLEDs usually dissatisfy people's needs, and traditional blue light exciting yellow phosphors lack red spectrum, which has low color rendering performance. At present, the red-green phosphor excited by blue LED can significantly improve its spectral saturation and color performance $[3,4]$, but the process of designing red, green, and blue color requires a lot of experiment and is timeconsuming. In view of these, we intend to predict WLED's color performance by constructing red and green laminated remote phosphor film model to achieve high-color rendering white LED efficiently. On the one hand, remote phosphor films applied to white LEDs can keep them away from the heat source of the chip and improve the reliability of the phosphor; on the other hand, it can improve the color uniformity of the white LED, and the laminated remote film can effectively avoid the reabsorption effect between the red and green film.

Due to the inadequate set of color samples, the traditional color rendering index (CRI) sometimes yields inaccurate predictions of color fidelity $[5,6]$. The Illuminating Engineering Society (IES) recently developed the IES TM-30-15 method. Compared with CRI, TM-30-15 has a set of 99 real-world color samples and the color space is more uniform [7]; it takes color fidelity $\left(\mathrm{R}_{\mathrm{f}}\right)$ and color gamut $\left(\mathrm{R}_{\mathrm{g}}\right)$ to quantify the color rendering performance. The index $R_{f}$, similar to the CRI $R_{a}$ index, is a numerical measure describing color fidelity that the similarity of colors rendered by the test source and reference illuminant. If no color shift occurs, $\mathrm{R}_{\mathrm{f}}$ will get a maximum score of 100 . Meanwhile, $R_{g}$ is a color gamut measure for assessing the variation in the chroma of 


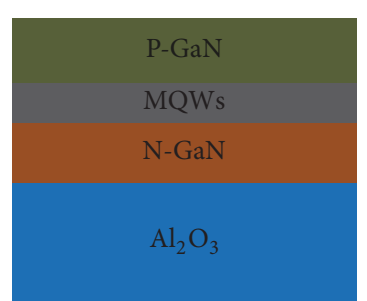

(a)

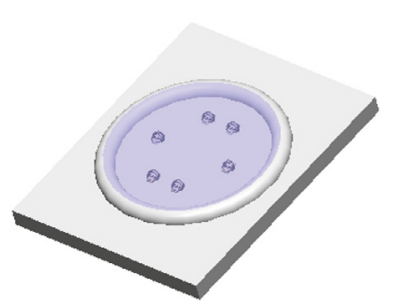

(b)

Figure 1: (a) The structure of blue LED; (b) the model of blue COB.

TABLE 1: The material parameters of each layer of blue LED.

\begin{tabular}{lccc}
\hline Layer structure & Thickness $(\mu \mathrm{m})$ & Refractive index & ${\text { Absorption coefficient }\left(\mathrm{mm}^{-1}\right)}$ \\
\hline P-GaN & 0.3 & 2.45 & 5 \\
$\mathrm{MQWs}$ & 0.1 & 2.54 & 8 \\
$\mathrm{~N}-\mathrm{GaN}$ & 4 & 2.42 & 5 \\
$\mathrm{Al}_{2} \mathrm{O}_{3}$ & 100 & 1.78 & 0 \\
\hline
\end{tabular}

illuminated objects, and if there is no variation in chroma, $R_{g}$ will get a score of 100 .

At present, CRI is always used to evaluate the color performance of WLED and the optimal spectra of WLED is usually obtained by a program for maximizing LER under conditions of CRI above high values [8-11]. However, these studies lack experimental data to validate their models and few people take TM-30-15 method to evaluate and optimize WLED's color performance. In this paper, we will introduce the optical models of red and green phosphors films based on Mie scattering $[12,13]$ and Monte Carlo ray tracing $[14,15]$ that can simulate the color performance of WLED at different phosphor concentrations, evaluate the simulated spectrum by TM-30-15 method, and then validate it by experiments.

\section{Experiments}

To fabricate phosphor films, red or green phosphor (made by Hilde) was mixed with silicone (made by KMT) and its refractive index is 1.41 . The peak values of emission spectrum of red and green phosphor are $655 \mathrm{~nm}$ and $535 \mathrm{~nm}$. The mixture was dispersed on a $0.2 \mathrm{~mm}$ thick metal spacer. In order to control the thickness of the phosphor film, another metal slide of the same size was pressed on the spacer. After curing for 1 hour, the two metal slides were removed, giving the phosphor film and taking out $10 \mathrm{~mm}$ diameter films with different concentrations. The PMS- 80 visible light spectrum analysis system of Yuanfang Optoelectronics was used to test the color parameters of white LEDs, and Malvern's NANOZS laser particle size analyzer was used to analyze the particle size distribution of phosphors. These tests were carried out at room temperature.

\section{Models and Results}

3.1. Chip-on-Board Light Source. The blue LED chip is the illuminating center of the chip-on-board (COB) light source and its dimensions were $0.36 \mathrm{~mm} \times 0.71 \mathrm{~mm} \times 0.11 \mathrm{~mm}$. The chip used in the experiment is a horizontal structure and the blue light is randomly emitted from the surface of the active layer. As is shown in Figure 1(a), the main structure is simplified: P-layer (P-GaN), Active layers (MQWs), N-layer $(\mathrm{N}-\mathrm{GaN})$, Sapphire (Al2O3) layers.

The material parameters of each layer are shown in Table 1 .

Figure 1(b) is a schematic diagram showing the arrangement of six blue LED chips on the substrate to form a COB light source. Based on the material parameters of each layer, the Monte Carlo ray tracing method is used to simulate the light source illumination, and the light intensity distribution of simulation and experimental comparison are shown in Figure 2. Figure 2 shows that the light intensity distribution is consistent with the Lambertian distribution:

$$
I(\theta)=I_{N} \cos (\theta)
$$

where the $I_{N}$ is the normal light intensity and $\theta$ is the angle between the light and the normal.

The fitness between the simulation and the experiment was analyzed by the normalized cross correlation (NCC). The NCC is given by the following.

$$
\mathrm{NCC}=\frac{\sum_{i}\left[I\left(\theta_{i}\right)_{m}-\bar{I}_{m}\right]\left[I\left(\theta_{i}\right)_{n}-\bar{I}_{n}\right]}{\sqrt{\sum_{i}\left[I\left(\theta_{i}\right)_{m}-\bar{I}_{m}\right]^{2}\left[I\left(\theta_{i}\right)_{n}-\bar{I}_{n}\right]^{2}}}
$$

The $I\left(\theta_{i}\right)_{m}$ and $I\left(\theta_{i}\right)_{n}$ are the simulated and the experimental light intensity value at the ray angle $\theta_{i}$, and $\bar{I}_{m}$ and $\bar{I}_{n}$ were the average value of $I\left(\theta_{i}\right)_{m}$ and $I\left(\theta_{i}\right)_{n}$, respectively. When the NCC value is closer to 1 , the fitness between the simulation and experiment is higher. The calculated NCC value of light intensity distribution of experiment and simulation reaches $99.72 \%$, which indicates that the constructed optical model can accurately describe the light intensity distribution of the actual light source. Figure 3 is 


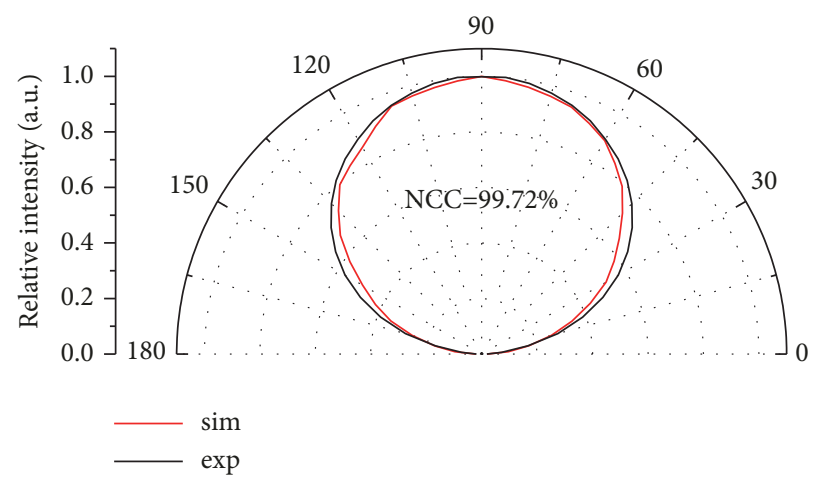

FIGURE 2: Comparison of light intensity distribution made by experiment and simulation.

a comparison of the simulated and experimental spectral distribution of the blue light source.

According to the NCC formula, the correlation coefficient of the spectral distribution of the $\mathrm{COB}$ source of the simulation and experiment reaches $99.91 \%$, indicating two spectral curves fit well and the simulated color coordinates $(0.1521$, 0.0282 ) are very close to the experimental color coordinates $(0.1522,0.0281)$.

3.2. Phosphor Model Based on Mie Theory. For a single phosphor particle, the scattering behavior can be described by Mie scattering. When the intensity is $I_{i n c}$ and the nonpolarized light of wavelength $\lambda$ is illuminated, the scattering light intensity $I_{s c a}$ at the scattering angle $\theta$ can be shown as follows [16-18]:

$$
\begin{aligned}
& I_{s c a}=\frac{1}{k^{2} r^{2}}\left(S_{11}\right) I_{i n c} \\
& S_{11}=\frac{1}{2}\left(\left|S_{1}\right|^{2}+\left|S_{2}\right|^{2}\right)
\end{aligned}
$$

where $S_{1}$ and $S_{2}$ are the scattering amplitude functions and $k$ is the wave number. The scattering cross section, the extinction cross section, and the absorption cross section of the single particle can be expressed as follows.

$$
\begin{aligned}
C_{s c a} & =\frac{I_{s c a}}{I_{i n c}}=\frac{1}{k^{2} r^{2}}\left(S_{12}\right) \\
& =\frac{2 \pi}{k^{2}} \sum_{0}^{\infty}(2 n+1)\left(\left|a_{n}\right|^{2}+\left|b_{n}\right|^{2}\right) \\
C_{\text {ext }} & =\frac{I_{\text {ext }}}{I_{\text {inc }}}=\frac{2 \pi}{k^{2}} \sum_{1}^{\infty}(2 n+1) \operatorname{Re}\left(a_{n}+b_{n}\right) \\
C_{a b s} & =C_{\text {ext }}-C_{s c a}
\end{aligned}
$$

When a plurality of phosphor particles is aggregated, the scattering and absorption can be expressed as follows.

$$
\begin{aligned}
& \mu_{a b s}=N C_{a b s} \\
& \mu_{s c a}=N C_{s c a} \\
& \mu_{e x t}=\mu_{a b s}+\mu_{s c a}
\end{aligned}
$$

The $\mu_{a b s}, \mu_{\text {sca }}$, and $\mu_{\text {ext }}$ are the absorption coefficient, the scattering coefficient, and the extinction coefficient, respectively, and $N$ is the number of particles of per unit volume. The calculation of the particle concentration $N$ is based on the measured particle size as shown in Figure 4 (D50 $=17.2 \mu \mathrm{m}$ for green phosphor, $\mathrm{D} 50=7.6 \mu \mathrm{m}$ for red phosphor) and is calculated according to the following formula:

$$
\rho_{\text {phos }}=\frac{N_{\text {phos }}}{V_{\text {total }}}=\frac{V_{\text {phos }}}{V_{\text {total }}\left[P_{1}(4 \pi / 3)\left(d_{1} / 2\right)^{3}+P_{2}(4 \pi / 3)\left(d_{2} / 2\right)^{3}+\cdots+P_{n}(4 \pi / 3)\left(d_{n} / 2\right)^{3}\right]}
$$

where $d_{1}, d_{2} \cdots d_{n}$ are the particle diameters of the phosphors and $\mathrm{P}_{1}, \mathrm{P}_{2} \cdots \mathrm{P}_{\mathrm{n}}$ are the volume distributions of the corresponding particle diameters, respectively.

3.3. Monolayer Phosphor Films Models. Figure 11 shows the light propagation in phosphor films and describes several phenomena occurring in monochrome layers which include two processes: The first process is the emission and transmission of blue excitation light. A part of the blue light is absorbed by the phosphor film, and another part of the blue light scatters and penetrates in the phosphor film layer. The second process is based on the blue light absorbed by the film layer of the first process to emit long-wavelength green light or red light and the absorbed energy intensity can be calculated by the following.

$$
\alpha(\lambda)=\frac{E_{x}(\lambda)}{E_{x}(\lambda)+E_{m}(\lambda)}
$$




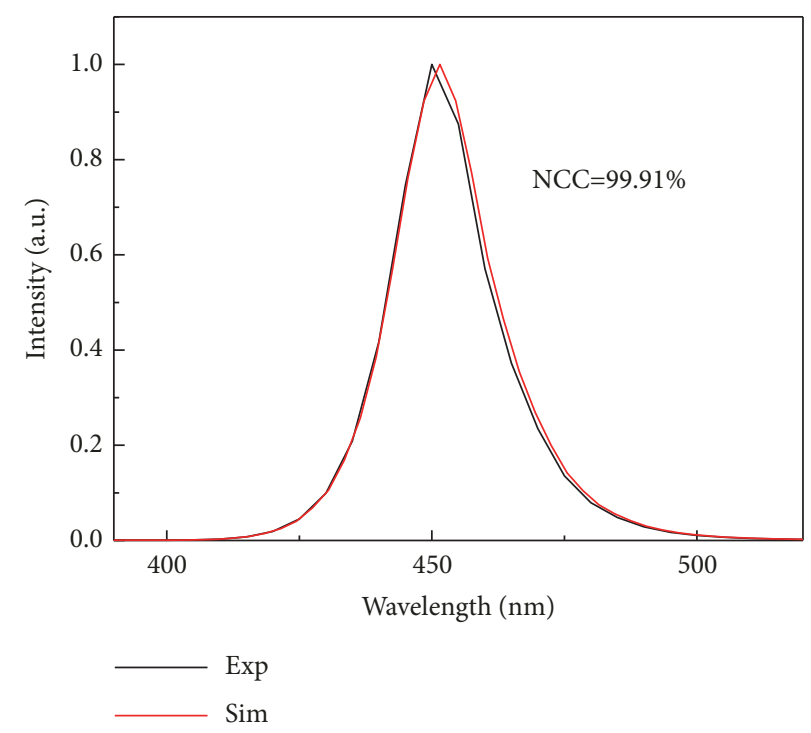

FIGURE 3: Spectrum of experiment and simulation.

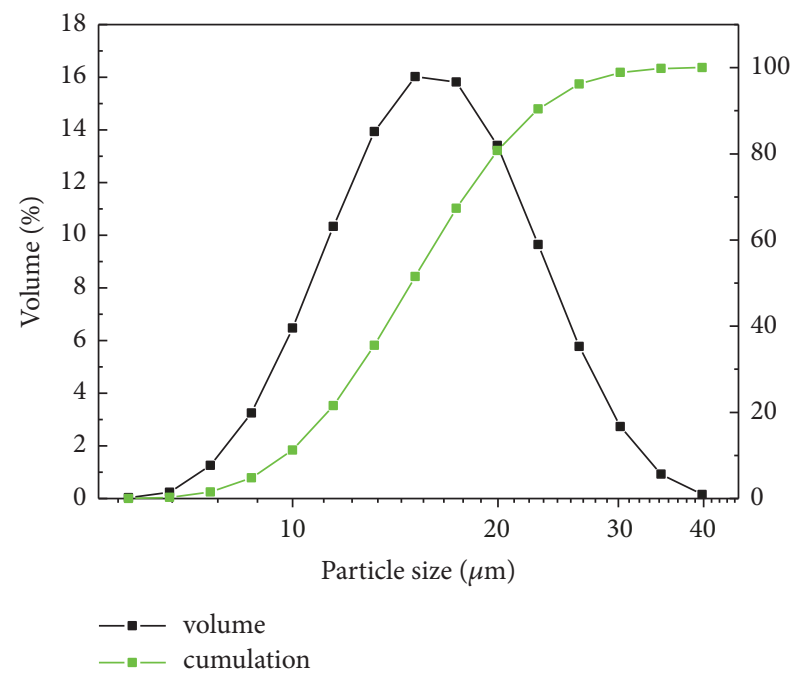

(a)

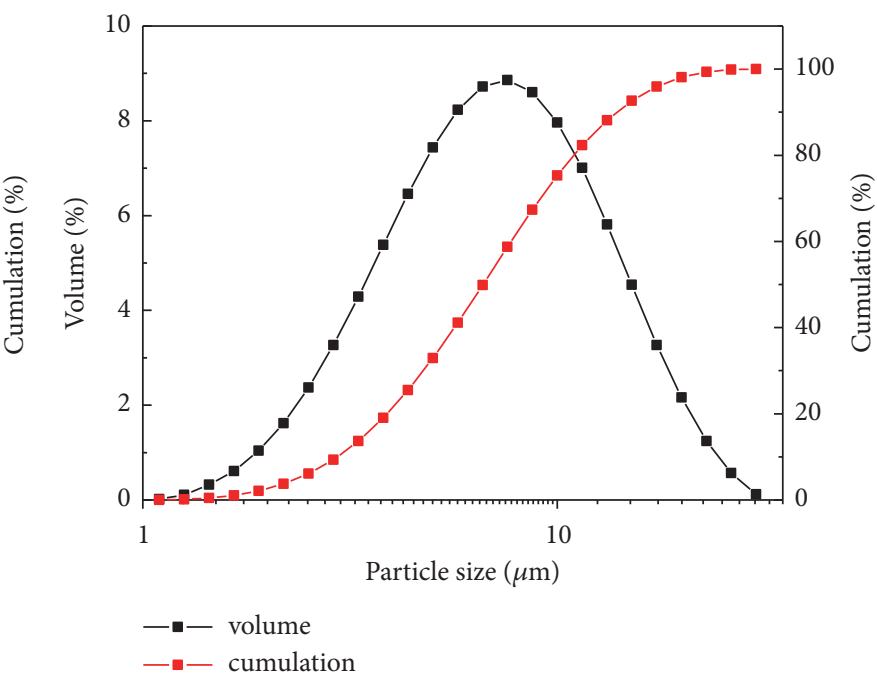

(b)

FIGURE 4: Measured phosphor particle size distribution (a) green phosphor; (b) red phosphor.

$\mathrm{E}_{\mathrm{x}}(\lambda)$ and $\mathrm{E}_{\mathrm{m}}(\lambda)$ are the excitation and emission spectrum of phosphors, which are measured by experiment (see Figure 5).

Figure 6 shows the phosphor film placed on the blue light $\mathrm{COB}$ source by an experimental frame, which is a hollow cylinder with a height of $4 \mathrm{~mm}$ and a radius of $25 \mathrm{~mm}$ and the surface was painted black.

Figure 7 shows the prepared green films. Based on the above optical model, the green phosphor films with a mass ratio of phosphor and silicone of $0.4: 1,0.5: 1,0.6: 1$, and $0.7: 1$ were spectrally simulated and the results are shown in Figure 8.

According to the simulation and experiments, the simulated results agree well with the experimental spectral distribution, and the correlation coefficient reaches $99 \%$.
Table 2 shows the relevant color coordinates calculated by corresponding spectrum.

Comparing the results of simulated and experimental color coordinates, we find that the error of the chromaticity coordinates of different concentration between simulation and experimental simulation is within 0.01, indicating that the green phosphor film optical model is established successfully.

The optical model of red phosphor film was established in the same way of the above-mentioned green phosphor film models. Red films with a mass ratio of 0.05:1, 0.1:1, 0.15:1, and 0.2:1 were prepared (see Figure 9). Figure 10 shows the simulation of the different phosphor concentrations which is consistent with the experimental spectrum, and the correlation coefficients are all above 99\%. According to its 

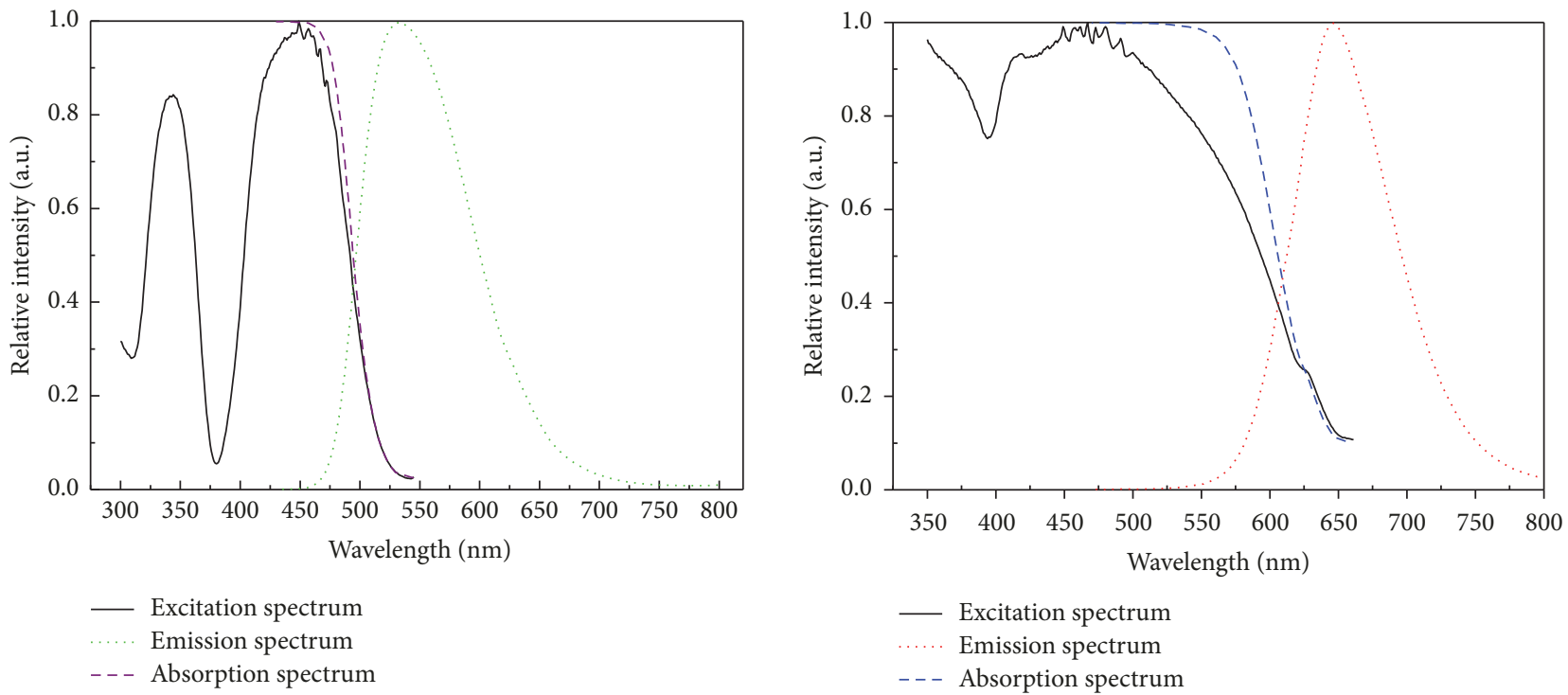

FIGURE 5: Experimental excitation, emission, and calculated absorption spectrum of green and red phosphors.

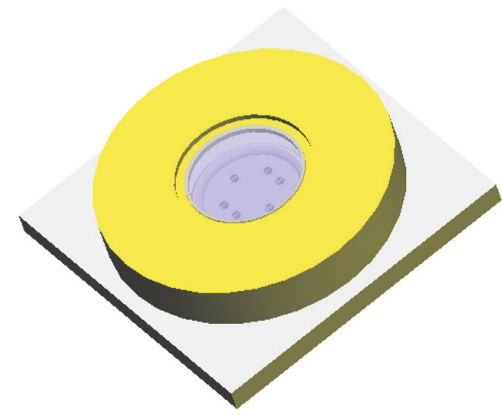

(a)

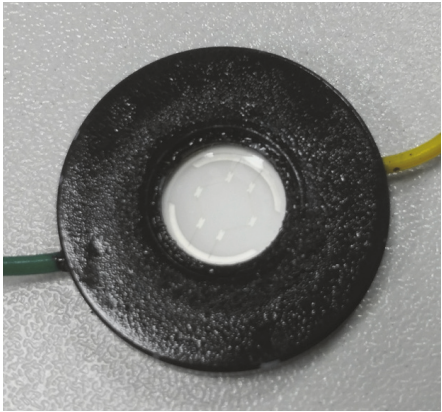

(b)

FIgURE 6: (a) Optical model of simulation; (b) optical structure of experiment.

spectral distribution, its corresponding color coordinates are calculated, as shown in Table 3.

Compared with the color coordinate results of simulation and experiment, the deviation of the chromaticity coordinates of different concentration between simulation and experimental simulation is within 0.01 indicating that the red phosphor film optical model is reasonable.

3.4. Double-Layer Phosphor Films. Based on the above optical model of red-green single-layer phosphor films, we established an optical model of red-green laminated phosphor film. Experiments and simulation were carried out by putting green phosphor film on the red phosphor film to alleviate reabsorption of green light.

As shown in Figure 11, the light propagation in the doublelayer phosphor films is described with four processes: the first process is that the blue LED emits blue light into the red and green phosphor film layers, some of the blue light is absorbed by the red and green phosphors, and the remaining blue light is scattered or penetrated out of the film layer; the second process is based on the blue light absorbed by the first process to excite red phosphor to emit red light; the third process is based on the blue light absorbed by the first process to emit green light, and part of the green light will be scattered and penetrated in the film layer, while another part of the green light will be absorbed by the red phosphor; the fourth process is based on the green light absorbed by the red phosphor in the third process, and the red light will be scattered and penetrated in the film layer.

In order to obtain the white light efficiently, the color distribution of different concentrations of red and green laminated remote phosphor films excited by blue light was analyzed by experiments. Figure 12 shows the color coordinates distribution of above green films with different concentrations of red films with a mass ratio of phosphor and silicone of $0.05: 1,0.10: 1,0.15: 1$, and 0.20:1.

When the mass ratio of red phosphor film is $0.05: 1$, any of the above-mentioned green phosphor films excited by blue light combining with it will emit white light and the chromaticity coordinates are close to the black body line. When any other concentration of red phosphor films combines with green phosphor films, it will emit reddish 


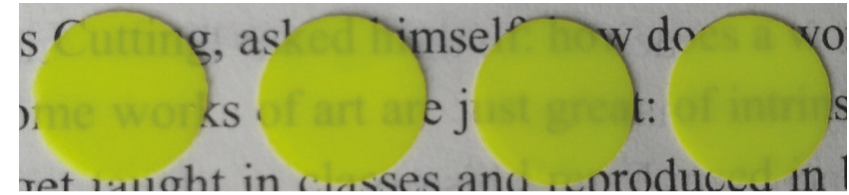

FIGURE 7: Green phosphor films with different concentrations (weight ratios phosphor: silicone = 0.4:1; 0.5:1; 0.6:1; 0.7:1).
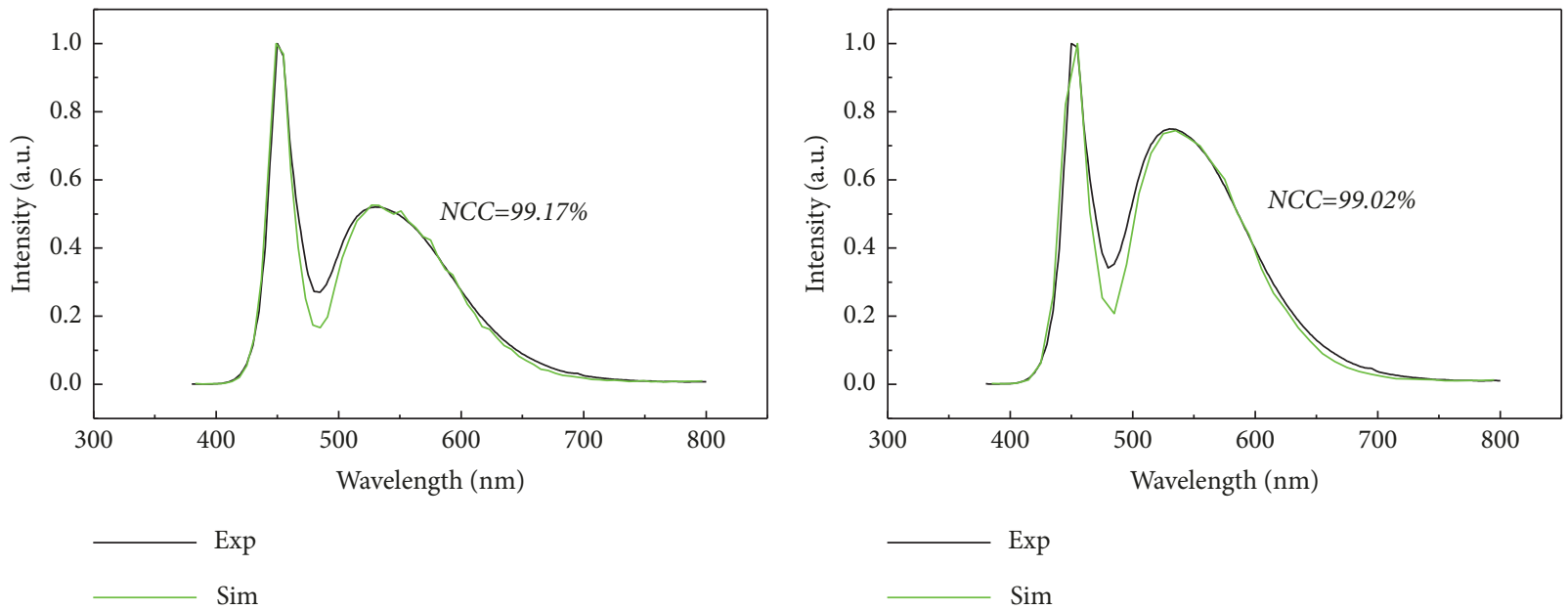

(a)
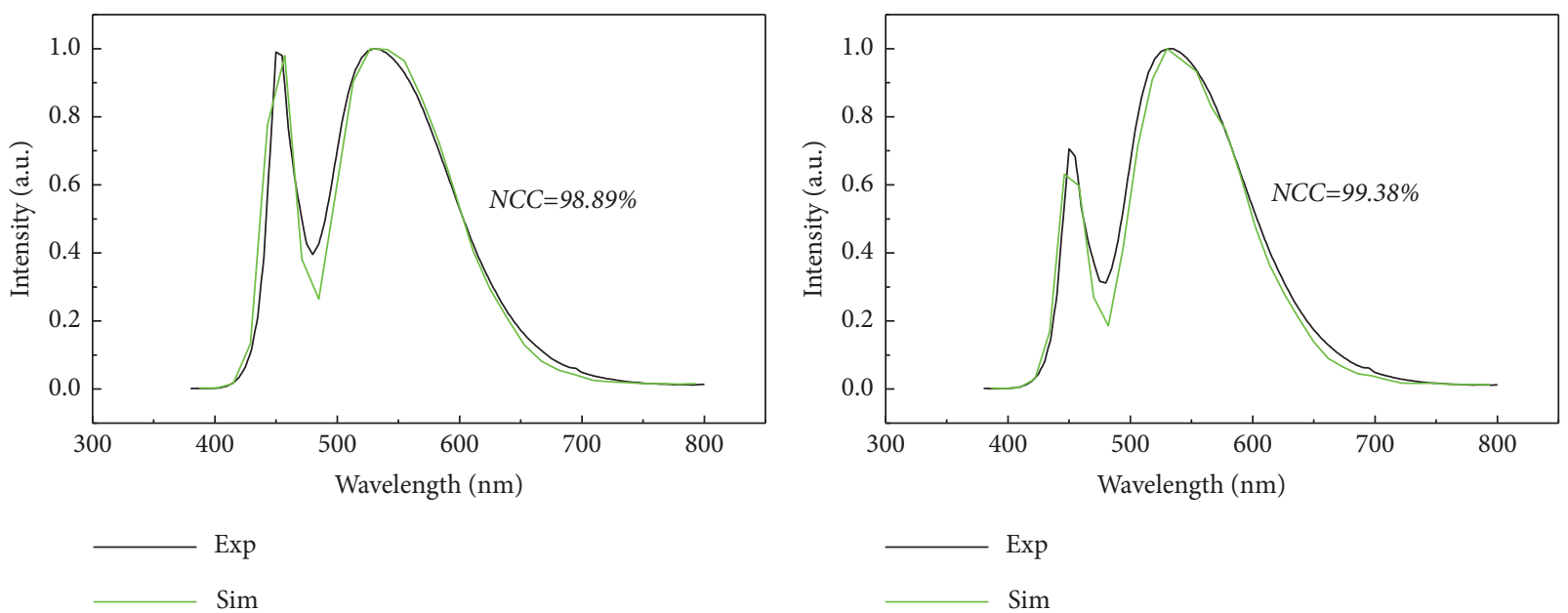

(c)

(d)

FIGURE 8: Spectrum power distribution of simulation and experiment at different mass ratio of green phosphor films (a) 0.4:1; (b) 0.5:1; (c) 0.6:1; (d) 0.7:1.

TABLE 2: Color coordinates of experiment and simulation at different mass ratios of green phosphor films.

\begin{tabular}{|c|c|c|c|c|}
\hline Concentration ratio & $\begin{array}{c}\text { Experimental } \\
C I E(x, y)\end{array}$ & $\begin{array}{c}\text { Simulated } \\
C I E(x, y)\end{array}$ & $\triangle C I E-x$ & $\triangle C I E-y$ \\
\hline $0.4: 1$ & $(0.2728,0.3339)$ & $(0.2752,0.3344)$ & 0.0024 & 0.0005 \\
\hline $0.5: 1$ & $(0.2902,0.3760)$ & $(0.2917,0.3739)$ & 0.0015 & 0.0021 \\
\hline $0.6: 1$ & $(0.3042,0.4097)$ & $(0.3035,0.4104)$ & 0.0007 & 0.0007 \\
\hline $0.7: 1$ & $(0.3211,0.4460)$ & $(0.3206,0.4440)$ & 0.0005 & 0.0020 \\
\hline
\end{tabular}




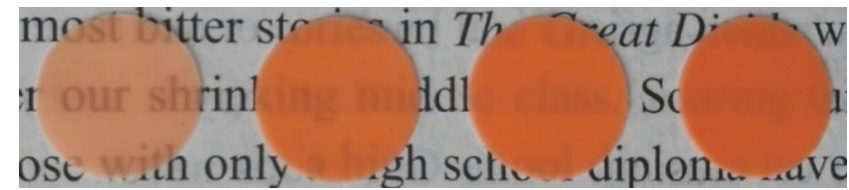

FIGURE 9: Red phosphor films with different concentrations (weight ratios phosphor: silicone $=0.05: 1 ; 0.1: 1 ; 0.15: 1 ; 0.2: 1$ ).
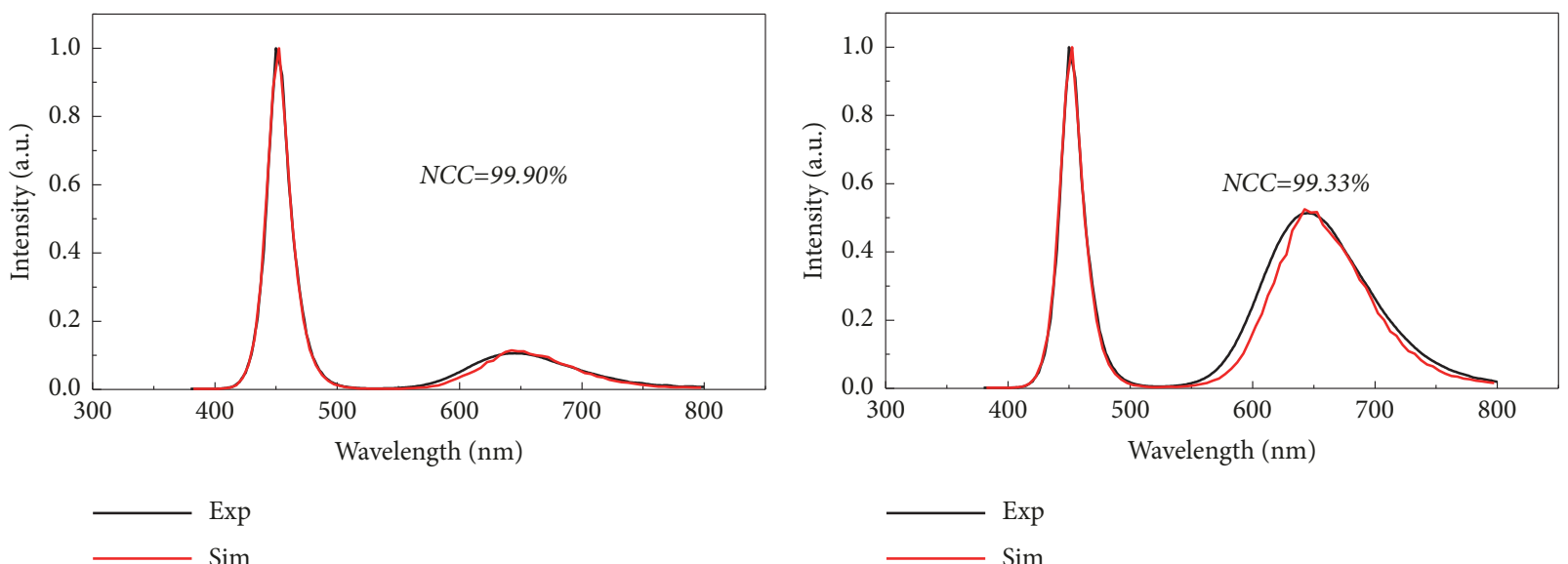

(a)
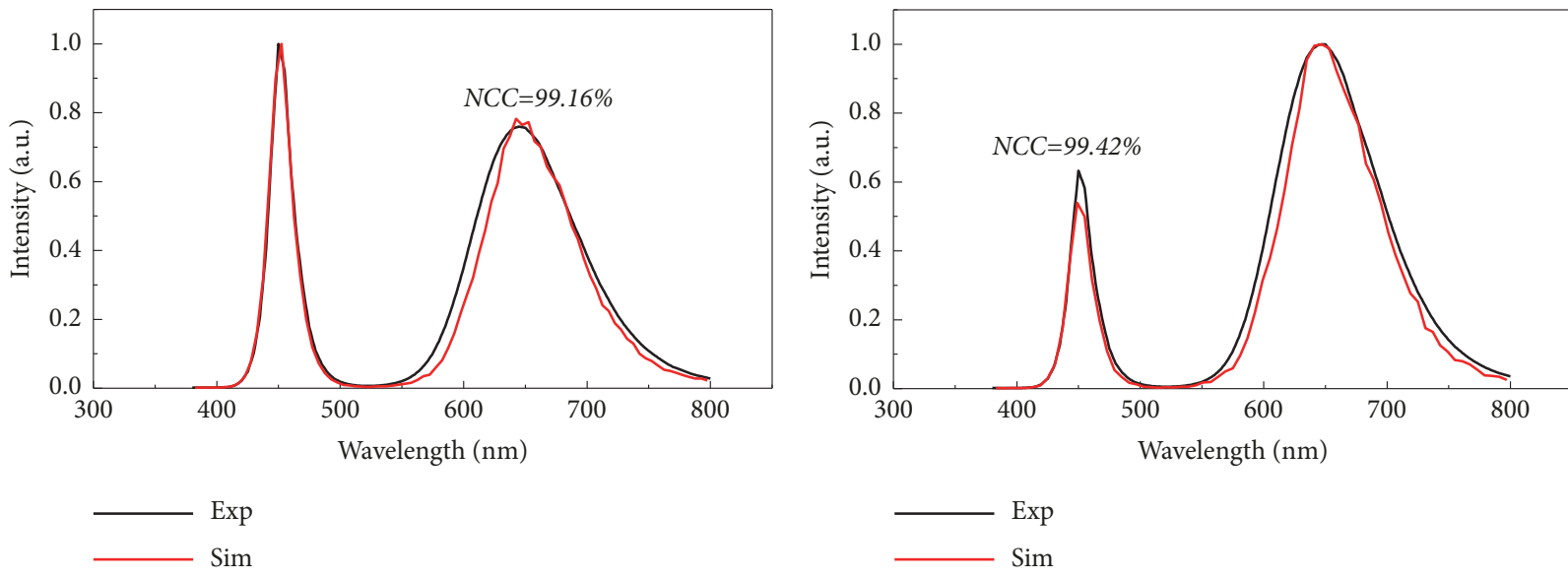

(c)

(d)

FiguRE 10: Spectrum power distribution of simulation and experiment at different mass ratio of red phosphor films (a) 0.05:1; (b) 0.1:1; (c) $0.15: 1$; (d) 0.2:1.

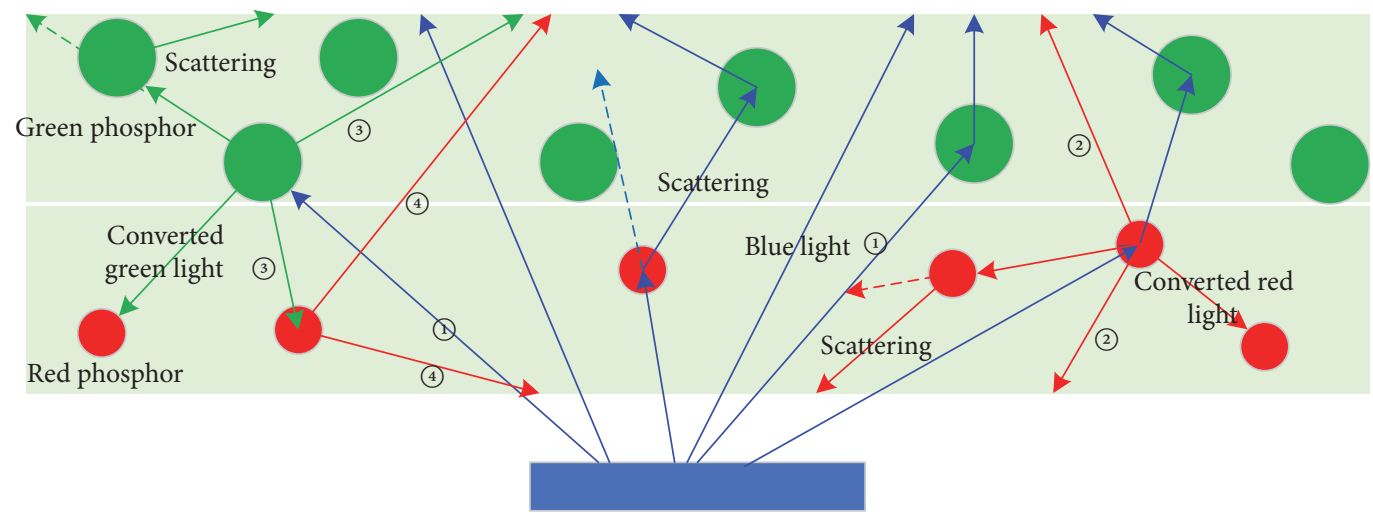

FIGURE 11: Schematic diagram of light propagating direction in phosphor films. 
TABLE 3: Color coordinates of experiment and simulation at different mass ratios of phosphor films.

\begin{tabular}{|c|c|c|c|c|}
\hline Concentration ratio & $\begin{array}{c}\text { Experimental } \\
C I E(x, y)\end{array}$ & $\begin{array}{c}\text { Simulated } \\
C I E(x, y)\end{array}$ & $\triangle C I E-x$ & $\triangle C I E-y$ \\
\hline $0.05: 1$ & $(0.2116,0.0678)$ & $(0.2007,0.0576)$ & 0.0109 & 0.0102 \\
\hline $0.1: 1$ & $(0.3455,0.1531)$ & $(0.3441,0.1406)$ & 0.0014 & 0.0125 \\
\hline $0.15: 1$ & $(0.3909,0.1811)$ & $(0.4109,0.1802)$ & 0.0200 & 0.0009 \\
\hline $0.2: 1$ & $(0.4766,0.2293)$ & $(0.4747,0.2170)$ & 0.0019 & 0.0123 \\
\hline
\end{tabular}

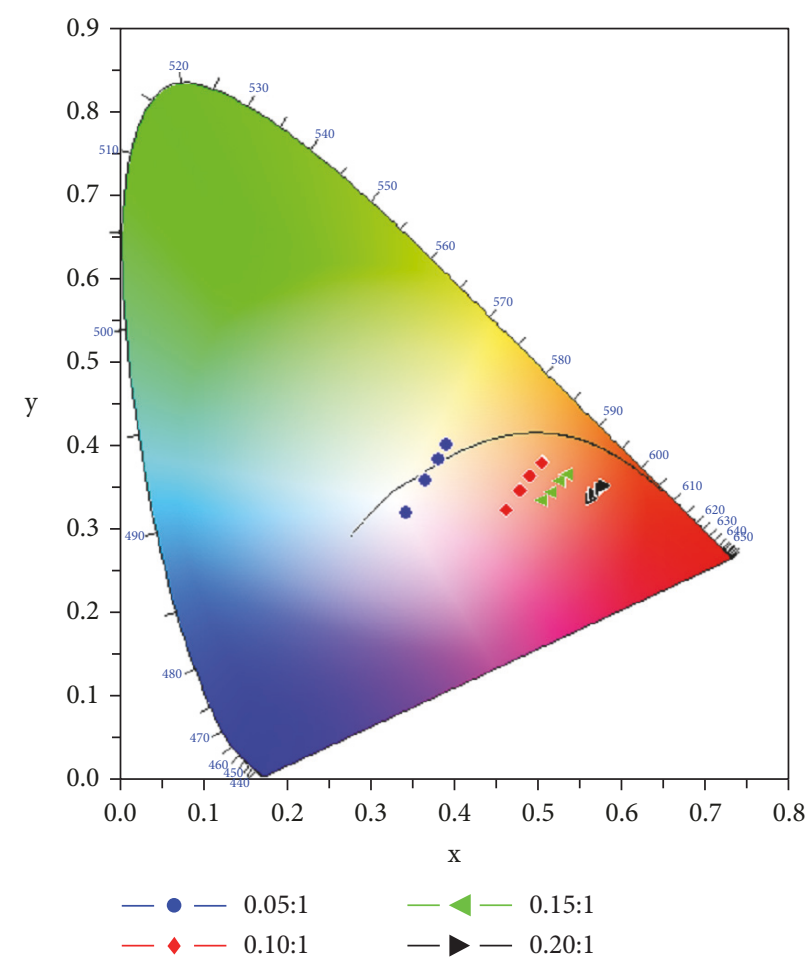

FIGURE 12: Color coordinates distribution of green and red laminated remote phosphor film layers.

light and the chromaticity coordinates are far away from the black body line. Therefore, we selected a red phosphor film with a mass ratio of phosphor and silicone of $0.05: 1$ with different concentrations of green phosphor films to do simulation. Figure 13 is a comparison of the spectral simulation and experimental comparison of the red-green laminated phosphor films with the red-green mass ratios of phosphor and silicone of 0.05:0.4, 0.05:0.5, 0.05:0.6, and 0.05:07, respectively.

Figure 13 shows the comparison of the simulated and experimented spectral power distribution, and the correlation coefficient NCC reaches 97\%, which indicates the established optical model of laminated phosphor films is meaningful. The possible error of simulation may be due to reabsorption of the green lights by the red phosphor. Figure 14 shows the comparison of the simulated and measured values of CRI and $\mathrm{R}_{\mathrm{f}}$. The maximum simulated value of CRI reaches 96 while the experimental result is 98 at the concentration ratio of $0.05: 0.5$. Due to the rigorous principle of TM-3015 , the $R_{f}$ values can be lower than CRI and the simulated result reaches 90 while the experimental value reaches 92 at the concentration ratio of 0.05:0.5. Figure 15 shows the errors between the simulated and experimental values. The maximum error of CRI between the simulated and measured values reaches 4 , when the $\mathrm{R}_{\mathrm{f}}$ value of the maximum error reaches 2 , which demonstrates that the established models predict the $R_{f}$ values more precisely than CRI values.

Figure 16 shows the comparison of the simulated and measured values of $R_{f}$ and $R_{g}$ based on the TM-30-15 method and the simulated results of $R_{f}$ and $R_{g}$ fit the measured values well, which demonstrates the established models can predict the spectrum of phosphor coated WLED and the $R_{f}$ and $R_{g}$ values can be calculated precisely according to the simulated spectrum. When the mass ratio of red and green phosphor is $0.05: 0.5$, the simulation result is optimal and $R_{f}=90, R_{g}=101$.

\section{Conclusions}

This study established the optical models of single-layer phosphor films based on Mie scattering theory and simulated the photoluminescence process of phosphor films based on Monte Carlo ray tracing method, and the correlation 

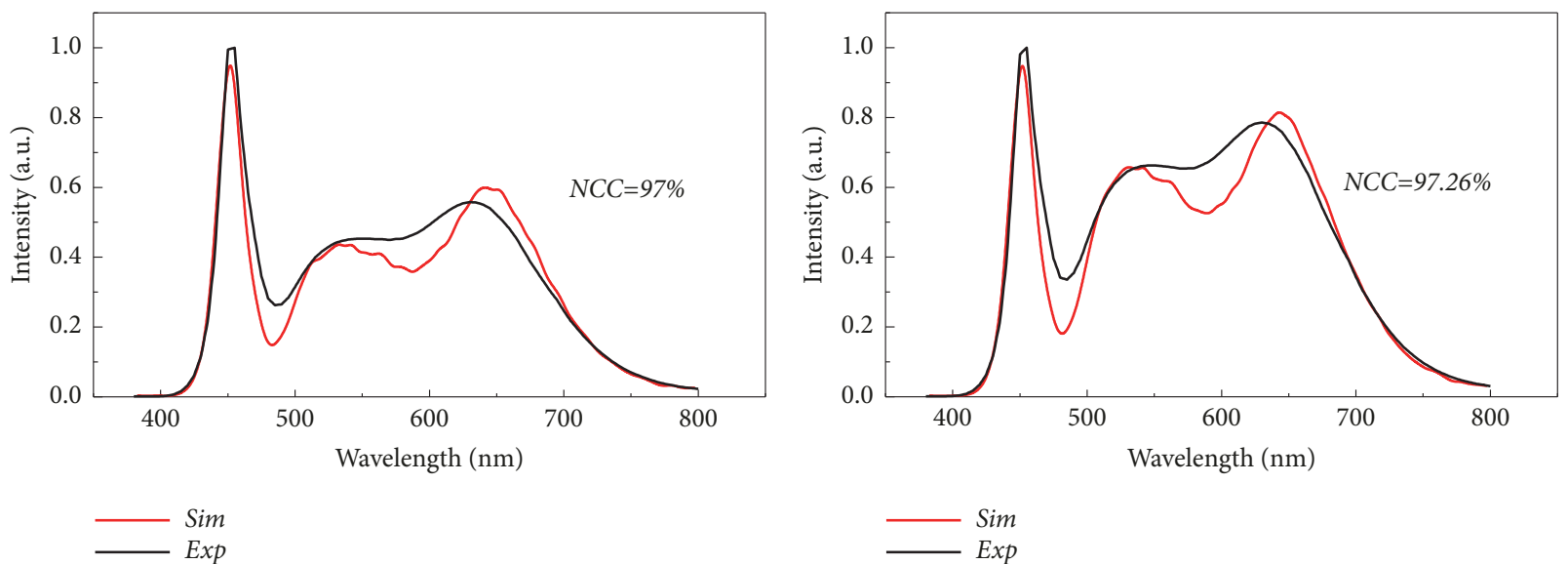

(a)
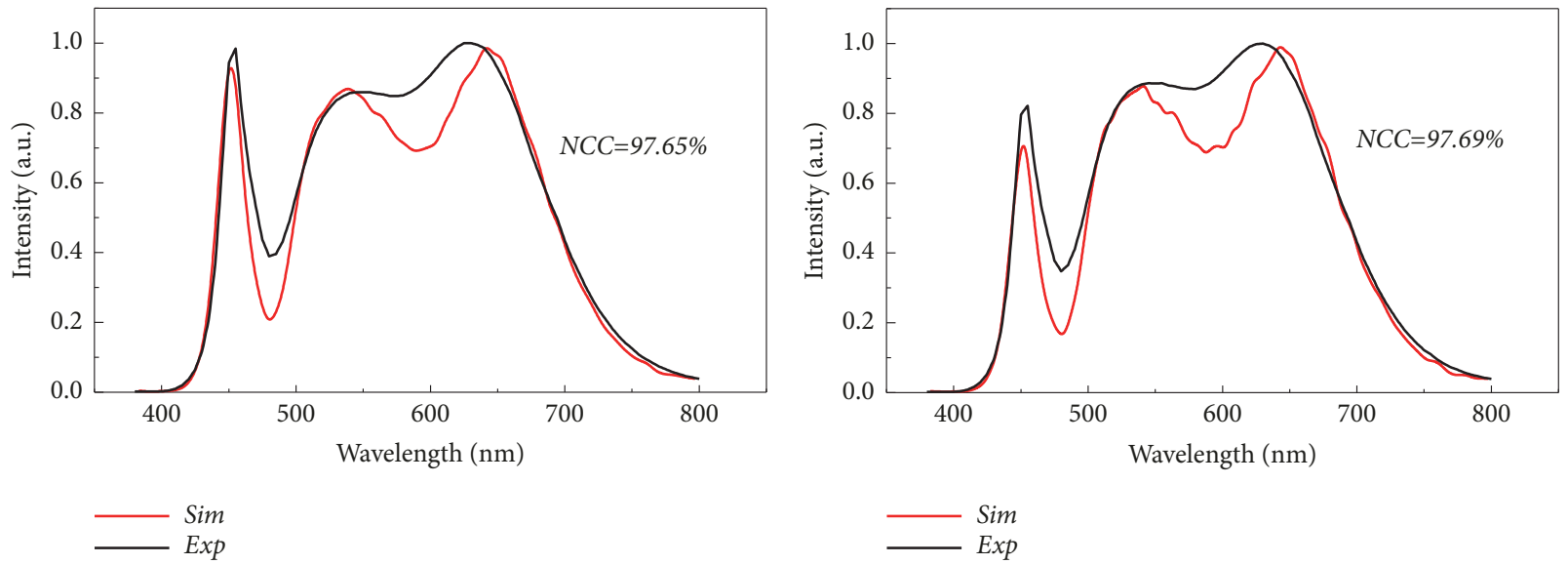

(c)

(d)

FIGURE 13: Spectrum power distribution of simulation and experiment at different mass ratios of green and red laminated remote phosphor films: (a) 0.05:0.4; (b) 0.05:0.5; (c) 0.05:0.6; (d) 0.05:0.7.

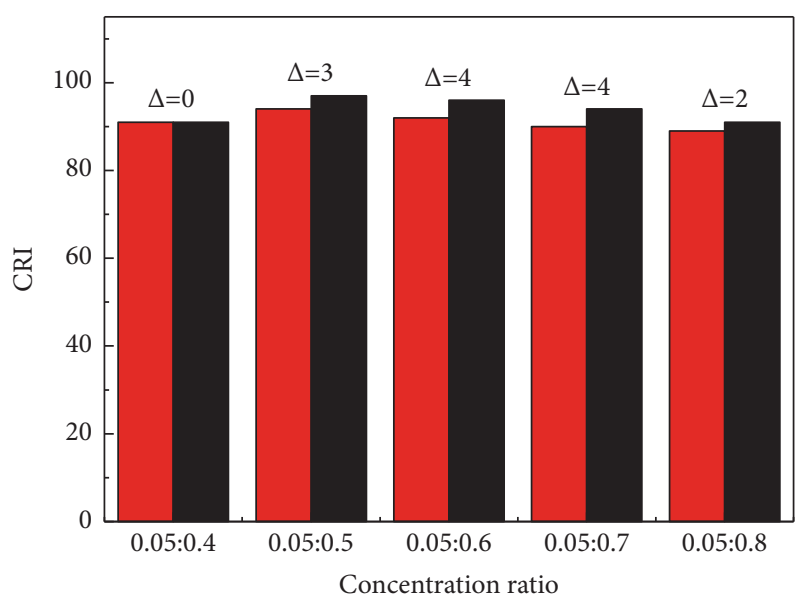

$\square \operatorname{Sim}$
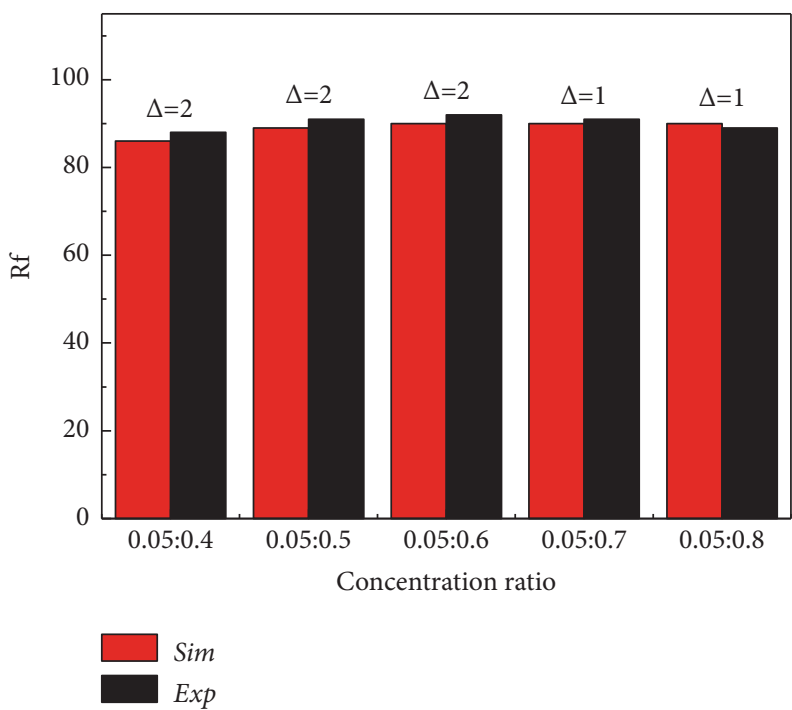

FIGURE 14: Comparison of $\mathrm{R}_{\mathrm{f}}$ and CRI made by experiment and simulation at different mass ratios of green and red laminated phosphor film layers. 


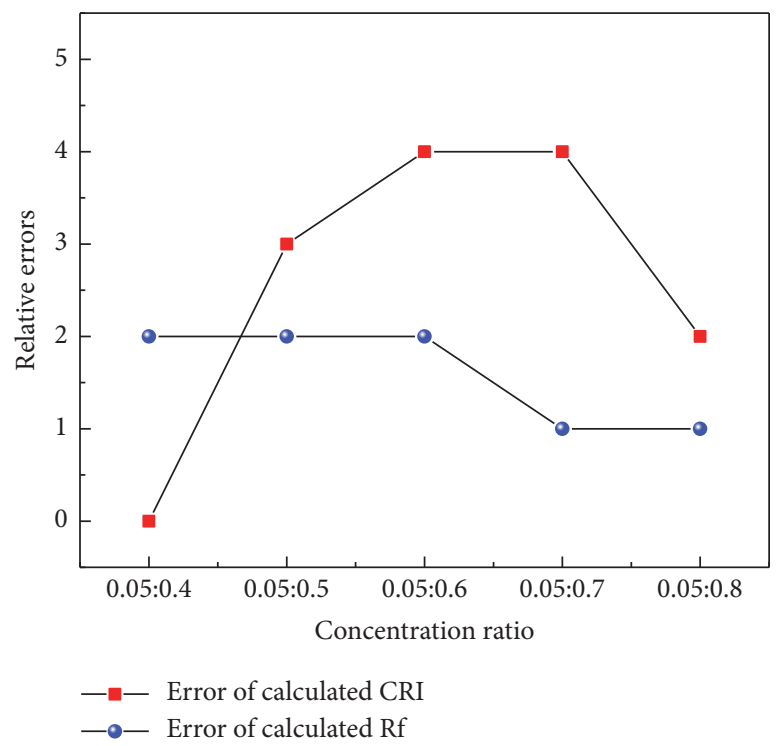

FIGURE 15: Errors of $\mathrm{R}_{\mathrm{f}}$ and CRI made by experiment and simulation at different mass ratios of green and red laminated phosphor film layers.
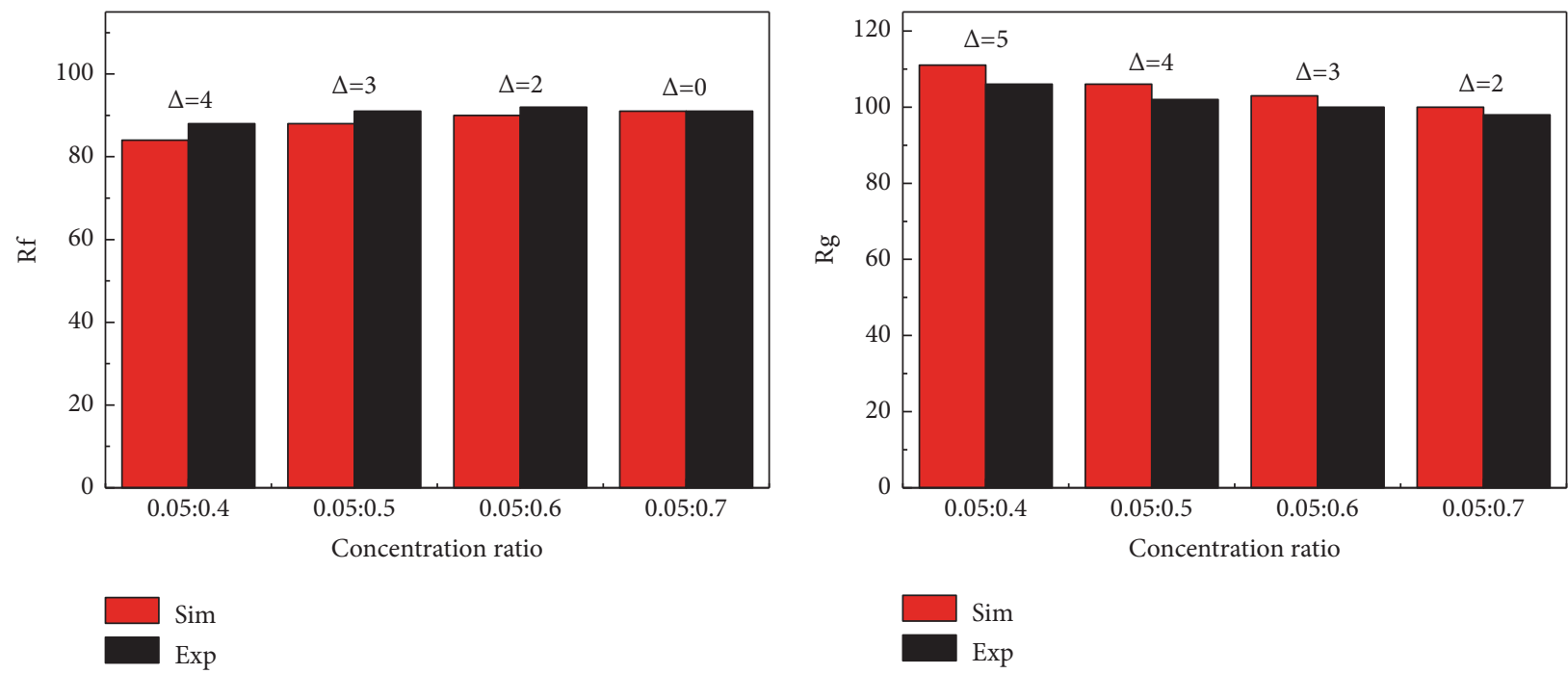

FIgURE 16: Comparison of $\mathrm{R}_{\mathrm{f}}$ and $\mathrm{R}_{\mathrm{g}}$ made by experiment and simulation at different mass ratios of green and red laminated phosphor film layers.

coefficient NCC of calculated and measured SPD reaches $99 \%$, which indicates that the simulation results fit well with the experiments. Based on the models of monochrome phosphor films, we established the models of red and green laminated phosphor films and the correlation coefficient NCC between the simulated and experimental results reaches $97 \%$, which demonstrates that the established model is reasonable. Then we use the more scientific and rigorous TM-30-15 color evaluation method compared with CRI to evaluate the color performance, and the simulated results well match the experimental results. Since the TM-30-15 has more color samples than CRI, we find that the established models predict more precisely $\mathrm{R}_{\mathrm{f}}$ values than $\mathrm{CRI}$ values and the established optical model of red-green laminated remote phosphor films can accurately predict $R_{f}$ and $R_{g}$ values based on TM-30-15 method. When the mass ratio of red and green phosphor is $0.05: 0.5$, the simulation result is optimal and $\mathrm{R}_{\mathrm{f}}$ $=90, R_{g}=101$. Through this research, we can predict the color performance of WLED and improve the design efficiency of WLED.

\section{Data Availability}

The data used to support the findings of this study are available from the corresponding author upon request.

\section{Conflicts of Interest}

The authors declare that there are no conflicts of interest. 


\section{Acknowledgments}

This work was supported by the National Key R\&D Program of China (grant numbers: 2016YFB0400600, 2016YFB0400605), the Natural Science Foundation of Jiangsu Province (grant number: BK20171128), and the Transformation of Scientific and Technological Achievements of Jiangsu Province (grant number: BA2017100). The authors would like to thank N. Zhang and Y. H Zhu for their insightful technical advice and useful support.

\section{References}

[1] P. Pust, P. J. Schmidt, and W. Schnick, "A revolution in lighting," Nature Materials, vol. 14, no. 5, pp. 454-458, 2015.

[2] H. Zheng, S. Liu, and X. Luo, "Enhancing angular color uniformity of phosphor-converted white light-emitting diodes by phosphor dip-transfer coating," Journal of Lightwave Technology, vol. 31, no. 12, pp. 1987-1993, 2013.

[3] Y. H. Won, H. S. Jang, K. W. Cho, Y. S. Song, D. Y. Jeon, and H. K. Kwon, "Effect of phosphor geometry on the luminous efficiency of high-power white light-emitting diodes with excellent color rendering property," Optics Letters, vol. 34, no. 1, pp. 1-3, 2009.

[4] B. C. Li, N. Z. Zhuo, W. Q. Li et al., "The preparation and properties study of high CRI white LED based on remote phosphor technology," Spectroscopy and Spectral Analysis, vol. 37, no. 3, pp. 728-732, 2017.

[5] Y. Ohno, "Spectral design considerations for white LED color rendering," Optical Engineering, vol. 44, no. 11, pp. 111302111309, 2005.

[6] A. David, P. T. Fini, K. W. Houser et al., "Development of the IES method for evaluating the color rendition of light sources," Optics Express, vol. 23, no. 12, pp. 15888-15906, 2015.

[7] A. David and L. A. Whitehead, "LED-based white light," Comptes Rendus Physique, vol. 19, no. 3, pp. 169-181, 2018.

[8] G. He and J. Tang, "Spectral optimization of phosphor-coated white LEDs for color rendering and luminous efficacy," IEEE Photonics Technology Letters, vol. 26, no. 14, pp. 1450-1453, 2014.

[9] G. He and H. Yan, "Optimal spectra of the phosphor-coated white LEDs with excellent color rendering property and high luminous efficacy of radiation," Optics Express, vol. 19, no. 3, pp. 2519-2529, 2011.

[10] D. Lin, P. Zhong, and G. He, "Color temperature tunable white LED cluster with color rendering index above 98," IEEE Photonics Technology Letters, vol. 29, no. 12, pp. 1050-1053, 2017.

[11] J. J. Zhang, R. Hu, X. J. Yu et al., "Color temperature tunable white led cluster with color rendering index above 98," Optical Laser Technology, vol. 88, pp. 161-165, 2017.

[12] H. C. V. D. Hulst, Light Scattering by Small Particles, Dover Publications, New York, NY, USA, 2012.

[13] H. Y. Wu and D. R. Jenkins, "Phosphor modeling and characterization,” Optical Engineering, vol. 53, no. 11, p. 114107, 2014.

[14] V. Y. F. Leung, A. Lagendijk, T. W. Tukker, A. P. Mosk, W. L. Ijzerman, and W. L. Vos, "Interplay between multiple scattering, emission, and absorption of light in the phosphor of a white light-emitting diode," Optics Express, vol. 22, no. 7, pp. 81908204, 2014.

[15] Z. Liu, S. Liu, K. Wang, and X. Luo, "Measurement and numerical studies of optical properties of YAG:Ce phosphor for white light-emitting diode packaging," Applied Optics, vol. 49, no. 2, pp. 247-257, 2010.
[16] C. F. Bohren and D. R. Huffman, Absorption and Scattering of Light by Small Particles, Wiley, New Jersey, NJ, USA, 2007.

[17] K. Y. Qian, J. Ma, W. Fu et al., "Research on scattering properties of phosphor for high power white light emitting diode based on Mie scattering theory," Acta Physica Sinica, vol. 61, no. 20, pp. 252-259, 2012.

[18] C. C. Sun, C. Y. Chen, J. H. Chang et al., "Linear calculation model for prediction of color rendering index performance associated with correlated color temperature of white lightemitting diodes with two phosphors," Optical Engineering, vol. 51, no. 5, p. 54003, 2012. 

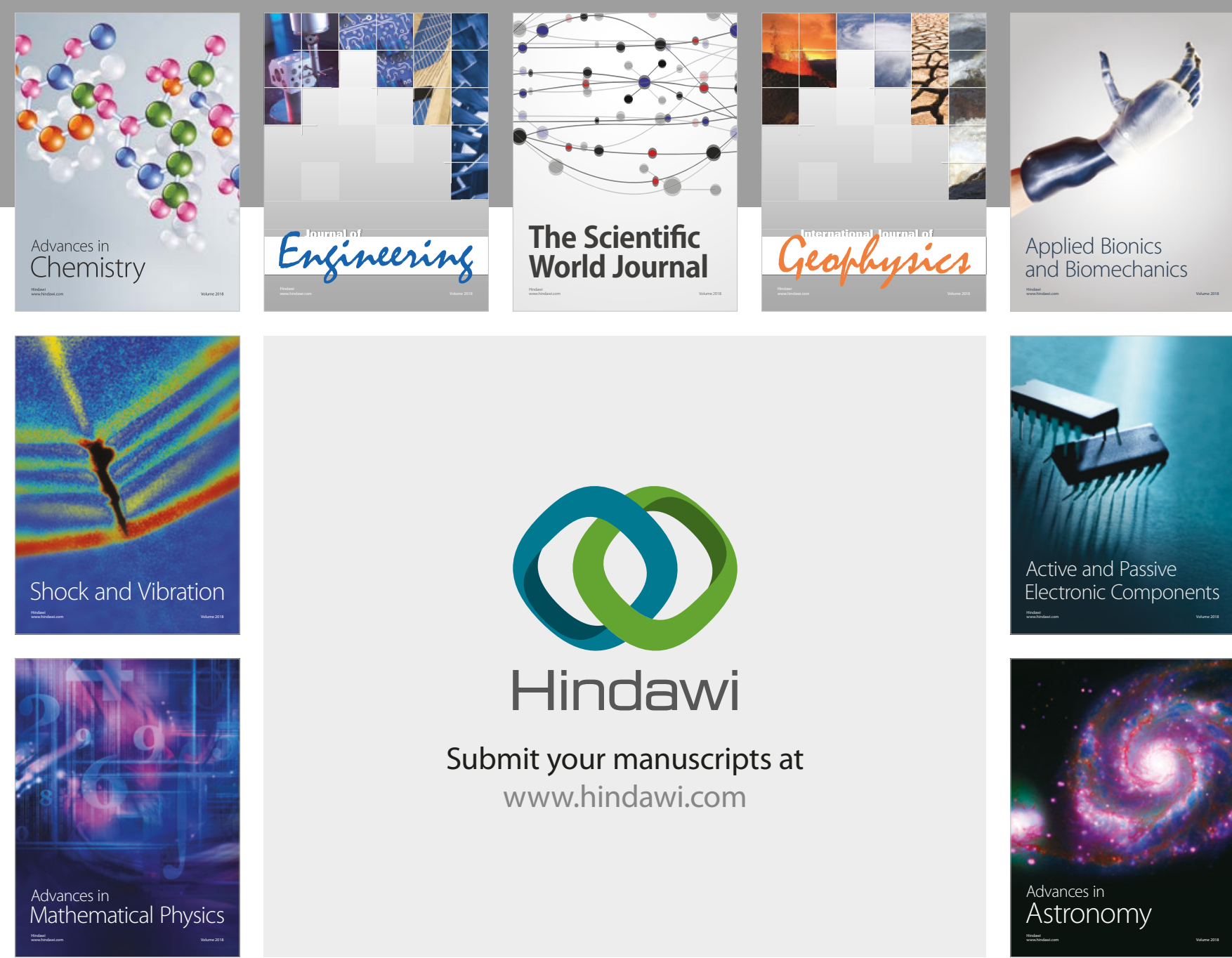

Submit your manuscripts at

www.hindawi.com

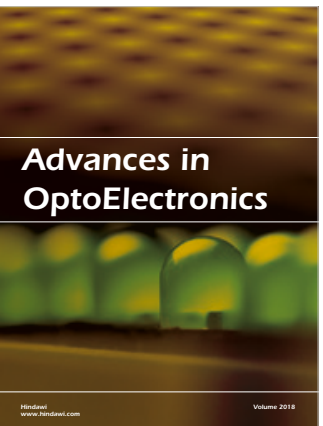

\section{Rotcting Machinery}
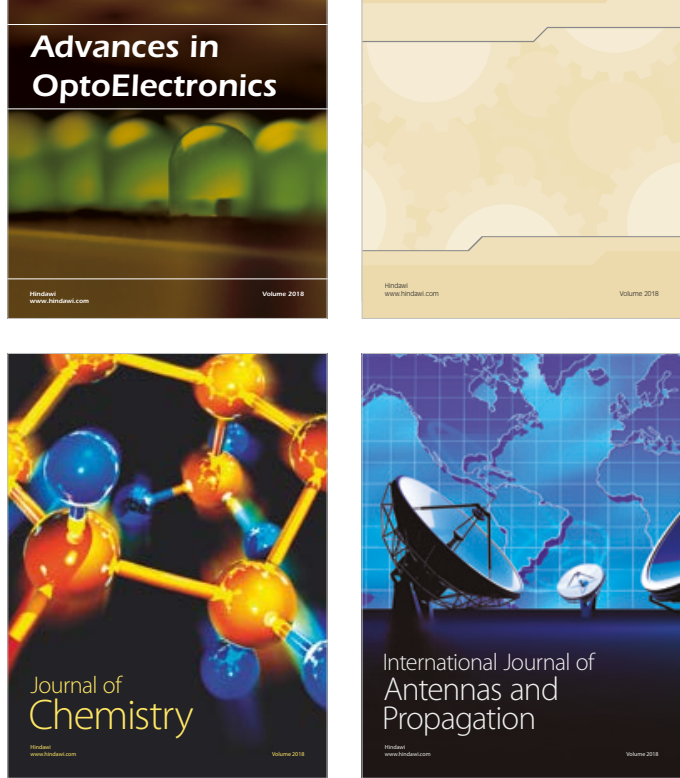

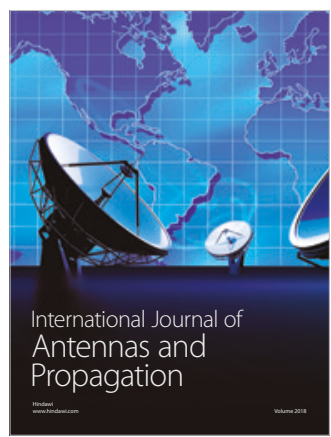

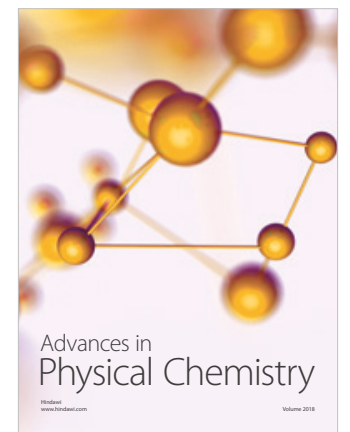

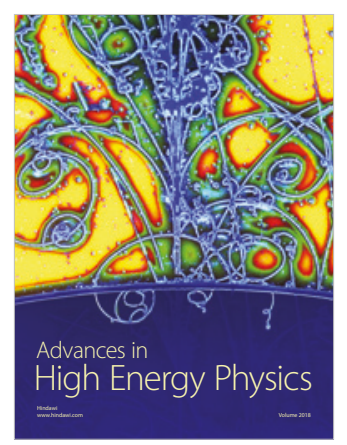

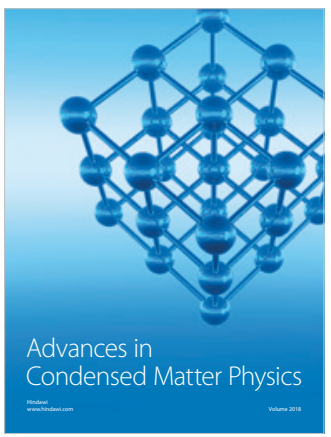

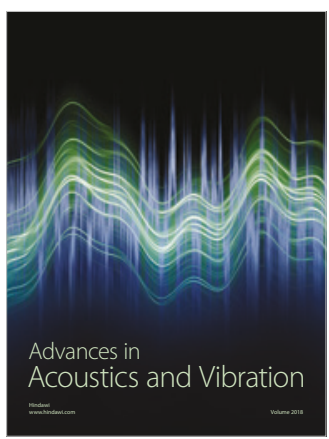

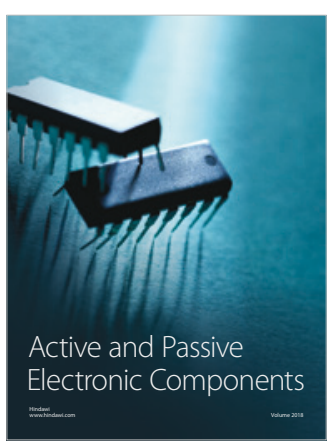
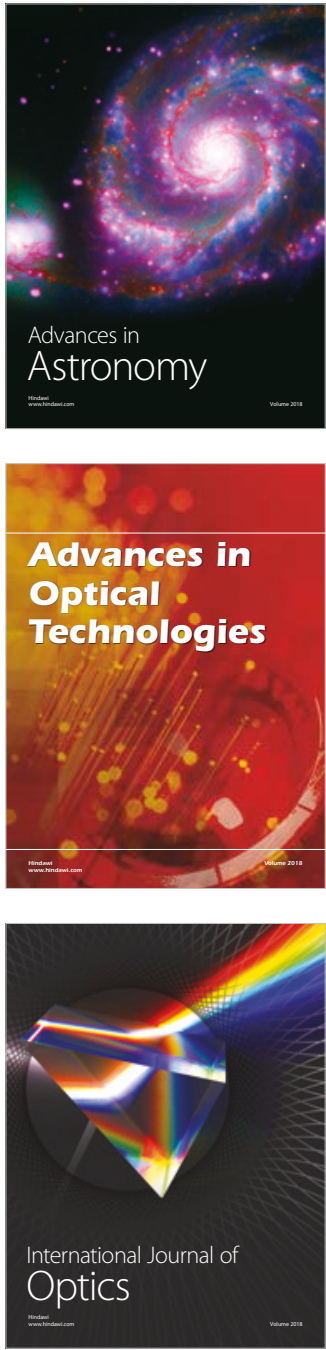